\title{
10
}

\section{ENRICHING 'HANDS ON HISTORY' THROUGH COMMUNITY DISSEMINATION}

\section{A case study of the Pebble Mill project}

\author{
Vanessa Jackson
}

Online platforms present us with opportunities to create and enrich hands on histories that complement and challenge traditional approaches. They support Andreas Fickers' assertion that "academic historiography has definitely lost its hegemonic power in the public sphere" $(2012,6)$. Fickers notes that the Internet offers abundant opportunities to share previously inaccessible sources with potentially unlimited users, but asks what kind of history this might produce. The Pebble Mill project, an online community archive focused on the history of BBC Pebble Mill in Birmingham, is one possible answer. It is not a history based on critical examination of documentary sources, within a culture of objectivity, with the aim of producing a synthesis of authenticated events in a scholarly, narrative form. Instead, the Pebble Mill project is a history of living people, written by the community whose past experience it is, and facilitated by me, as archivist, chronicler, interpreter, and citizen curator. Documentary sources, and particularly artefacts, are critically examined, albeit not necessarily in a scholarly manner, and particular events are retold in a narrative form, but there is no pretence of objectivity, because the writing concerns the community's lived experience. How the actors in these particular events felt and the position they took are germane to the narrative, and at the heart of their history. This is a qualitatively different kind of resource. It is an informal history, often written in the form of an online conversation, rather than academic prose. It is partial, subjective, and in places lacks accuracy, but it is the history that the community chooses to write, and to share, about itself. This imbues the resulting historical text with a different kind of authenticity, and a different kind of value. Though they may lack the academic rigour of a traditional history, such collections have a place in the archival world. They provide complementary collections to the institutional repositories, and to 'official' histories. 
'Hands on history' is a concept open to diverse interpretation. Fickers and van den Oever's plea was for a practical approach to historical enquiry, where - through physically interacting with artefacts - we stimulate our sensory understanding of the past $(2014,273)$. However, the methods through which we get our hands on the history can be varied, and I will argue here that the physicality of the process is not as important as the grass roots interrogation of historical artefacts, which could, in fact, occur in a virtual space.

One of the challenges for hands on history is how to disseminate the experiential encounter with the historical materials to a broader audience, in a manner that does not revert to traditional written history. If the physicality of the encounter is at the crux of the method's success, then how can this be replicated beyond the experience of the individual participants? The necessity now is to explore diverse methods of engaging wider audiences with hands on history, particularly through online means. Experimentation using online media archaeology laboratory spaces can result in new historiographical practices.

This chapter explores one application of hands on history: the Pebble Mill project, which employs a hands on approach to the creation and dissemination of multimedia artefacts, in the process producing what Dougherty and Schneider (2011) term an 'idiosyncratic archive'. The project is a democratic community history endeavour to document the history of BBC Pebble Mill. This chapter focuses upon the enrichment of histories through engagement with the online community, and the rewards and difficulties that result from facilitating them. The project provides an example of social media functioning as a laboratory for a community of memory around the practices of television production. As the project unfolds, social media communities interact with the collaborative online oral history, with the platforms becoming the space and means to encourage, share, manage, and interpret 'hands on history'.

\section{The context of the Pebble Mill project}

I worked in television production at BBC Birmingham for 20 years, leaving in 2008 , and this is the source of my interest in documenting its unofficial history. I began the Pebble Mill project in 2010 as a piece of academic research, and have seen it grow to a collection of over 1600 artefacts, as a result of community involvement. Through the project I have become a 'citizen curator', learning to navigate through the various challenges which have presented themselves at various points along the journey.

Pebble Mill was the first purpose-built broadcast centre in Europe to combine radio and television production (BBC 1962). It opened in Birmingham in 1971 and closed in 2004. At its height it produced around 10 per cent of BBC output (Wood 2005), boasting a renowned drama department, producing Nuts in May (1976, BBC Two) and Boys from the Blackstuff (1982, BBC Two) among many other programmes. The prolific factual unit produced the original series of Top 
Gear (1977-2001, BBC Two), Countryfile (1988-present, BBC One) and Gardeners' World (1968-present, BBC Two), in addition to live studio programming such as Pebble Mill at One (1972-1986, BBC One). Much of Pebble Mill's output falls under Frances Bonner's definition of 'ordinary television', with an emphasis on factual formatted programming incorporating 'real people' (2003). These types of programme are often neglected in terms of scholarship and critical acclaim, and their history is not as well documented as those in the traditional canon.

The Pebble Mill project consists of a website and a Facebook page with over 1600 members, many of whom are former BBC employees. As a former colleague I have a personal connection to many members of the online community. Blogs are regularly posted on the website and copied to Facebook, where most of the community activity happens: comments and new artefacts are added by participants, facilitating lively online discussion. There is a symbiotic relationship between the website and Facebook page, with social media driving traffic to the website, and individuals commenting on Facebook, with the content then copied back to the website.

\section{Towards a wider interpretation of hands on history}

Fickers and van den Oever (2014) define 'hands on history' in a literal fashion, stressing the physical encounter in stimulating our sensorial understanding of the past. Whilst this proves very effective in the context of an individual or small group of investigators, it is challenging to expand its scale. This interpretation of hands on history appears quite narrow in its scope, and I suggest the adoption of a less literal definition, which could yield similarly valuable results, whilst having the benefits of scalability.

Through the operation of the Pebble Mill project I have developed a practice of 'citizen curation', which I consider to be hands on in a more figurative sense. The role of the 'citizen curator' will be explored in more depth later in this chapter. The majority of artefacts on the Pebble Mill project website (www.pebblemill. org) have been donated to me by members of the online community which has grown up around the project. These artefacts are frequently remediated digital versions of analogue texts, including photographs of productions, people and their workplaces. Members also contribute videos, audio, and written material including script pages. Sometimes I am given a physical artefact, but more usually I receive a digitized version. Other artefacts are produced specially as part of the project: these include career biographies written by members of the online community, video oral histories created by me to document staff's working lives, and contemporary photographs of staff and memorabilia. Some of the video oral histories include demonstrations of defunct production equipment, which would be encompassed in Fickers and van den Oever's literal hands on history. However, I consider the engagement with all these artefacts in the online laboratory of social media as hands on history. It is the online community's hands on their own history: many individual hands on many small pieces of history, which when combined create a “textual memory product" (Keightley and Pickering 2012). Collecting the pieces 
of this particular historical jigsaw puzzle is a worthwhile endeavour in its own right, but the really valuable part of the exercise comes when the remediated artefacts are shared and built-on by the very community that created them in the first place, and this is where the hands on history is enriched in a laboratory-like space by the layering of more hands upon it.

\section{Creating and sharing hands on history}

For the Pebble Mill project, the really hands on historiography happens on social media, and specifically on Facebook. This is where the online community interacts with the historical material, by including their own experiences and memories, and adding further artefacts. This activity echoes citizen science and public history projects. Much of my practice centres on facilitating and moderating the sharing of historical artefacts online with the community involved with their original production. In order to understand how the process of enrichment occurs, it is necessary to consider some particular examples.

In October 2017 I posted a photograph on the Pebble Mill Facebook page (see Figure 10.1). It dates from 1983 and shows a local radio engineer, Rod Fawcett, standing beside the Radio WM (West Midlands) radio car, parked behind the garage at Pebble Mill. The radio car would be driven to a location and enabled live broadcasting from the scene. I asked if anyone could add any information about the radio car and how it worked, and members of the online community responded to the request. The post reached over 3500 people, 39 individuals 'liked' it and 29 people took the trouble to comment on it. This was a relatively high level of engagement for the page.

I have selected some of the comments posted in reaction to the photograph, to illustrate how the original artefact is built upon by the online community.

Keith Butler: I was attached as an engineer to Radio WM in 1983, and it was me who went down to Brookmans Park to collect this radio car and drive it back to Pebble Mill.

Bob Chesworth: UHF transmitter to that aerial on top of the mast, VHF comms to and from base. Air compressor to drive mast up (with safety overrides!) . . . A lot of the vehicles had number plates reflecting the transmitter, Lincs was A219 SUL 'cos we were 219 on medium wave...

Keith 'Scouse' Brook: Before I became a Pebble Mill cameraman, I worked at Radio Merseyside in the late 60s. Their radio car was a Ford Cortina and the whole of the cargo area filled with very heavy car batteries to power the transmitter. This made driving the thing great fun especially around corners when we were trying to stay close to a blue light police escort! Trying to get a signal back was problematic and the car had to be inched backwards or forwards until the signal strength was good enough. There was a switch at the base of the antenna to inhibit driving with it extended. To perform the 'inching' procedure, the switch was over-ridden with an old penny piece wedged between the contacts! 


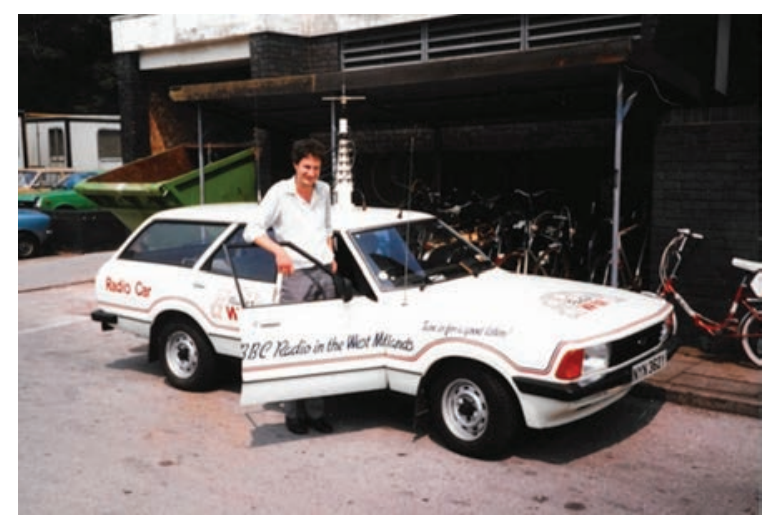

FIGURE 10.1 Former Radio WM engineer, Rod Fawcett, with the Radio WM radio car. (Photo by permission of Rod Fawcett)

These first-hand testimonies provide a historical context around the original artefact which would be difficult to replicate without social media. We learn, from the Radio WM engineer, how he collected this particular vehicle and drove it back to BBC Pebble Mill. We hear about the technical equipment in the car, and that the same cars were in use across all $\mathrm{BBC}$ local radio stations, which provides us with a useful national picture. The idiosyncrasies of the car's handling, because of the weight of the equipment, and the details about how to over-ride the safety cut-out switch, which prevented driving with the mast up, could only be added by someone who had used it professionally, and demonstrate the challenges of operating customized broadcast equipment. This kind of detail would be unlikely to be recorded in any institutional archive, because of the power dynamics around how archival documents are collected, with artefacts coming from 'official' - usually managerial - sources, rather than those reflecting the 'unofficial' experiences of the staff. Therefore, comments explaining the lived experience of using broadcast equipment become an extremely valuable resource in idiosyncratic archives, and prove the effectiveness of a social media laboratory approach. The contextual information that the comments provide add to the history being told. It is the result of motivated individuals remembering having their hands on a historical artefact. The photographic artefact rekindles the memory of physically interacting with the radio car, and the commenters take pleasure in sharing their memories with each other, and adding to the comments already posted.

The type of artefact used to stimulate the engagement of the online community can be varied, and the medium does not appear to dictate the value of the responses. Social media allows members of the online community not simply to add comments in response to posts, but to add their own artefacts as well. This phenomenon creates a virtuous circle, where one artefact leads to the digitization and display of another, which then leads the conversation, and therefore the history being written, in another direction. Considering a specific example will help explain the process. 


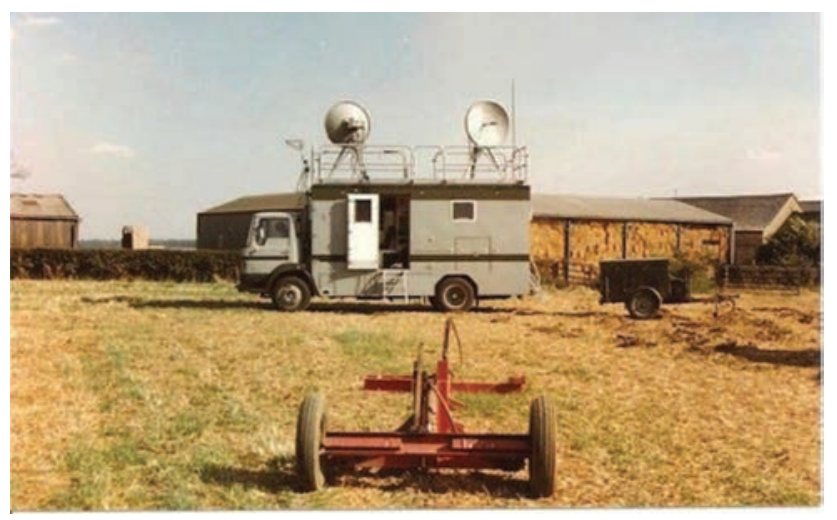

FIGURE 10.2 A BBC Radio links vehicle at Burghley Horse Trials. (Photo by permission of Steve Dellow)

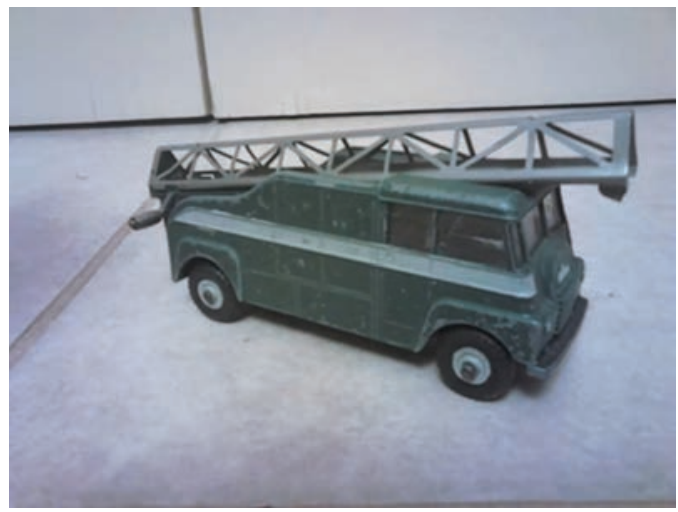

FIGURE 10.3 Eagle Tower Dinky toy. (Photo by permission of Cyril Thompson)

In January 2017 I posted a 1985 photo of a radio links vehicle at the Burghley Horse Trials (see Figure 10.2). I copied the post onto Facebook, and asked the online community to explain how the radio links worked in relaying the signal from an outside broadcast to either a BBC centre or a main transmitter. A number of engineers explained how the process worked technically, and by way of illustration, posted up their own photographs. Telescopic towers were often necessary to relay the signal with a line of sight to a radio links vehicle. A member of the Pebble Mill online community, Cyril Thompson, added a photograph of the Dinky toy version of the Eagle Tower, a mobile tower used for transmitting outside broadcast signals. He had found the toy in the waiting room at his dentist's office. Another engineer, Stuart Gandy, added a 1980 photograph of BBC Pebble Mill's actual Eagle Tower, and Steve Dellow added a photograph of rigged Eagle Towers in operation at Silverstone, during the British Grand Prix. 


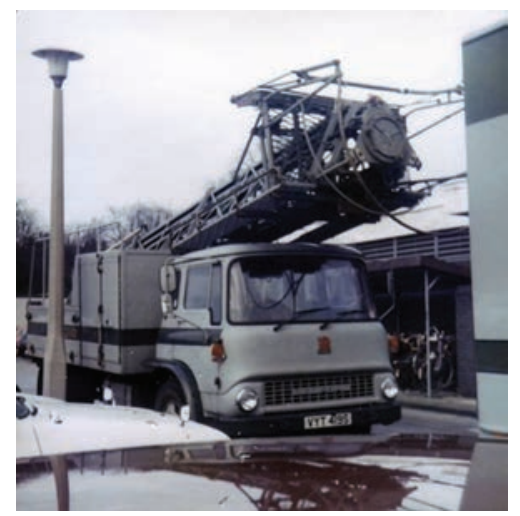

FIGURE 10.4 Pebble Mill Eagle Tower. (Photo by permission of Stuart Gandy)

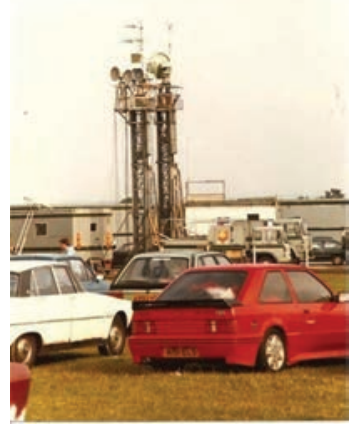

FIGURE 10.5 Rigged Eagle Towers at Silverstone. (Photo by permission of Steve Dellow)

Steve Dellow also scanned and posted the communications planning sheet from the Burghley Horse trials of 1985, which relate to the photograph I had originally posted. The radio links vehicle shown is number '356' on the planning sheet, and Steve was stationed at Tinwell Lodge (see the fourth column on the sheet). As part of his duties Steve needed to pay the landowner, a farmer, f25 for parking the vehicle on his land, plus $£ 20$ for the previous year, which had not been paid. The planning sheet gives an insight into the intricate preparations that accompanied each outside broadcast, and provides a fascinating contextualization to the photographs.

The artefacts that were added by the Pebble Mill online community in response to the original radio links vehicle photograph, sparked several related posts on the website, as I re-purposed the material from the Facebook page. This supports the notion of the community carrying out its own hands on historical investigation, determining what it chooses to include and share in a laboratory-like setting. 


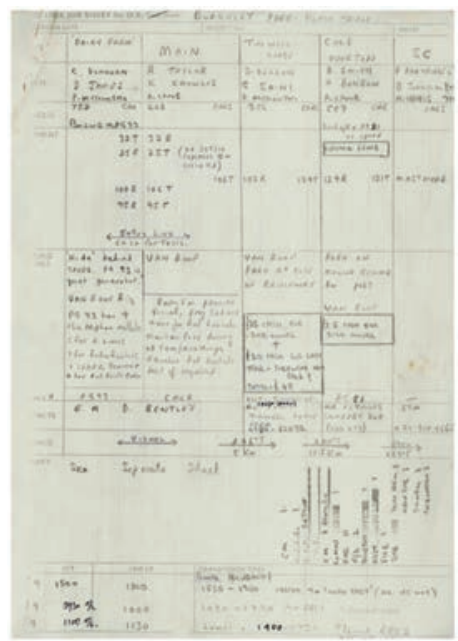

FIGURE 10.6 Outside broadcast communications sheet. (Photography by permission of Steve Dellow)

\section{The role of the citizen curator}

I consider my role in the Pebble Mill project as that of a 'citizen curator'; I select, organize, look after, and present the history of the community that has grown around the project. Without someone carrying out this complex role and facilitating the online interaction the project would lose momentum. To curate is to care: a curator is the keeper or custodian of a collection, derived from the Latin 'curare', to take care of. 'Taking care' is a crucial aspect of the role, and extends to the care of the artefacts which are entrusted to me, the care of the history being told, and having a duty of care towards the project's participants. It is an ethical position involving a sensibility of care and a responsibility to the community. Caring for the materials and also the contributors, and their memories, suggests a shift from museum curation around the care for artefacts, to the wider care for the participants as well, as part of a 'living heritage', involved in the production of a living history. When projects involve oral histories, and continued interaction with an active community, extending a duty of care to include the contributors is entirely appropriate. This indicates a development in the curation role, and the necessity of a flexible approach which can respond to the demands of the project, rather than following traditional curatorial practice.

Citizen curation is a manifestation of engaged citizenry, and shares similarities with the better documented examples of citizen science, as well as community or alternative media and public history. It is part of what James Curran describes as "a new culture, that is critical, selective and participatory" (2003, 227). Jonathan Silvertown defines the citizen-scientist as a volunteer who collects and sometimes even processes data as part of a scientific study $(2009,467)$. In a similar vein Clemencia Rodriguez coined the term 'citizens' media' to encompass community, 
radical, participatory and alternative media, highlighting the transformative effects from participants to active citizens (2003, 190). Such citizens provide labour, skills and enthusiasm at no monetary cost. However, the scale of activity differs hugely between projects. A citizen-science project may simply involve an hour's garden birdwatching as part of the Royal Society for the Protection of Birds' annual 'Big Garden Birdwatch'. Running a hyperlocal news site, or curating a community history project like that of the Pebble Mill project, requires sustained commitment on a daily basis. It is akin to a job, with (self-imposed) responsibilities and deadlines.

The citizen curator is in a position of power. They are taking care of a collection, deciding what belongs in that collection, how it is preserved and importantly they are the gate-keeper of it, making judgements on who has access and in what circumstances. Bailey et al. note that the Internet can be "ab(used) by those who hold the power, to give participants the illusion of participation" $(2008,106)$. I am conscious of the privileged and powerful position I hold, and feel a responsibility to use this power wisely, with the best interests of the community and the project at heart. The position of power distinguishes the curator from the community, even if they are embedded within it.

I want to care for the collection as best I can, but I have a very different approach to gate-keeping to most professional curators, because disseminating the archive openly and publicly is at the heart of the project. This does not mean, however, that there are no controls in place. There is moderation, although the operation is light-touch. In terms of the website, the first time a person comments, I as administrator have to approve it, thereafter that commenter is approved. This prevents the posting of spam or abusive comments. On the Facebook page, as administrator I can delete any inappropriate posts, but I have found that it is generally more effective for the online community to police itself. In the past contributors have realized when a comment they have written is inappropriate and have edited it themselves, or other members of the community have made it clear through the use of an emoticon when a comment makes them angry or upset. There are challenges that can occur, such as conflict becoming apparent within a project. In running the Pebble Mill project I have observed occasional hostility between different groupings within the community, or tension between staff who worked at Pebble Mill and outsiders, and negativity or abuse towards individuals featured on the site, due to incidents in the past. Deciding how to manage conflict can require careful thought on a case by case basis, particularly if an intervention is necessary.

Curation requires the selection of material, meaning that some material is discarded or unexplored; this process circumscribes the history being told. There are some unsavoury aspects to Pebble Mill's past that the community chooses not to remember publicly, for example, allegations of inappropriate sexual behaviour, or the dismissal of staff. The online community has never discussed these subjects, and I do not feel that it is appropriate for me to push them to confront them, although individuals have on occasion mentioned them to me privately. I feel that I would be stepping outside my role if I behaved more proactively here, and 
I would risk alienating members of the online community. This does raise questions concerning the nature of the history being told, which risks presenting a sanitized version, reflecting nostalgically on the past, rather than addressing difficult issues. I would argue that I am led by the community on what is included in the history, and would not describe the Pebble Mill project as an objective history. Rather it is a subjective account written by and for the community who has created it. If the history was an academic account of BBC Pebble Mill then these issues should be included, but when it is a community-driven endeavour, then it should include what the community chooses to share. There is a tension between the desire to articulate all aspects of Pebble Mill's history, and the sensitivities towards unsavoury aspects of it.

It is tempting to concentrate on the positives of efforts like the Pebble Mill project, but it is important to consider the ethical role of the citizen curator at the centre of such collaborations, and to caution against overzealous sharing. The citizen curator moderates content and decides what should, and what should not, be included in the 'idiosyncratic archive'. It is his or her hands on the community's memories. Some decisions are very easy to make: if a personal comment is made about someone's private life, it is straightforward to see that a line has been crossed, however, there is an area of semi-public/private comments, where the issue is more nuanced, and where it is easy to make a poor decision. Nick Couldry describes areas of the Internet as a "private subzone of public space", and this is where ambiguities arise over what participants perceive as public or private (2003, 51). I have found funerals to be particularly sensitive subjects regarding the public/ private divide, and here I have learnt by my mistakes. I am frequently alerted to the deaths of former colleagues, and funeral details are shared with me. I often post the details on the Pebble Mill website and Facebook page, as people may wish to attend a former colleague's funeral. However, it is easy to intrude on a family's grief, as I discovered when a widow contacted me, after being offended that I had posted details of her husband's funeral. She felt I was encouraging people to take advantage of her hospitality, which was not my intention. I apologized and removed the post. Since then I have adjusted my practice, and now only post funeral details on the Facebook page, keeping posts about the deaths of BBC staff on the website very neutral, concentrating on their BBC history, and avoiding details about their deaths. This incident illustrates the need to adapt one's practice in the light of experience, and to be aware of the duty of care towards individuals. There are ethical boundaries that require careful consideration, especially in balancing the tensions between privacy and reputation, against community interest and historical record. New historiographical methods require new ethical frameworks and guidance, which are only now beginning to emerge.

\section{The era of collaborative online oral history}

The examples in this chapter have illustrated how the Pebble Mill virtual community, facilitated by me as its citizen curator, builds the online archive that documents the history of the broadcast centre, through a hands on interaction with 
historical media artefacts. Shared visuals and text evoke memories in others, who are prompted to contribute their own individual responses, which then builds the history further, with each person adding their piece of the collective jigsaw puzzle. The new digital media ecology created by social media for contemporary short-term memory work enables us to write history in new ways. The Pebble Mill project uses these platforms for historical remembering, and harvests the articulated memories from the online community.

The use of interactive online platforms to create hands on histories, through initiatives like the Pebble Mill project, constitute a paradigm shift in the writing of oral histories. We are now entering the era of collective, online, oral history. The interrelationship of the process of historiography and the creation of a collective textual memory product is crucial here, and both have interactive online platforms at their core. This form of online oral history projects presents us with new ethical challenges, with a duty of care needing to be extended to participants.

Flinn et. al. draw attention to the role of archives in stimulating memory (2009, 76), and this is what we see in practice with the Pebble Mill project: the posting of a media artefact online evokes memories, which are captured, curated, and then fed back to enhance the archive itself. The examples seen earlier in this chapter, concerning how artefacts are posted and commented upon, are testament to this new departure in oral history writing. The examples illustrate how, why, and what individuals contribute to the project, and demonstrate how this creates an idiosyncratic archive, telling a history using an experimental method that would be impossible through other means. This process demonstrates social media's ability to transform non-fictional narrative, by effectively crowd-sourcing it in a nonlinear fashion, a concept which questions Cobley's assertion that "social media have not wrought a transformation of narrative any more than email or telephone did" (2014, 186). Social media does have the ability to transform non-fictional narrative, and to collectively build a multi-authored, non-linear, multi-media oral history. The artefacts and stories to be included in the Pebble Mill history are predominantly chosen and donated by members of the online community. They are then remediated by me on the website and Facebook page, with some additional information, followed by the online community building on the original post with their comments, anecdotes and further photographs or additional artefacts. This is a circular creative process by which the community collectively produces their own history. Through this process a multiplicity of views is gathered, which provide a context far more nuanced than would be possible in an institutional archive, with personal first-hand testimony being key, rather than an institutional perspective. How individuals react to a particular multi-media blog post is not necessarily predictable, with some seemingly innocuous posts eliciting high response levels, and online conversations frequently taking an unexpected direction, but this adds to the democratic empowerment of the community, leading and authoring the collection down particular paths.

What is not yet clear is the extent to which other community projects will exploit the possibilities of collective, online, oral history making. In time the 
opportunities afforded by interactive technologies are likely to become more visible to community and oral history projects, and the historians involved will hopefully capitalize on them, facilitating many communities in getting their hands on their own histories, interpreting and enriching them in the process.

\section{Bibliography}

Bailey, O.G., B. Cammaerts, and Carpentier, N. (2008) Understanding Alternative Media. London: Open University Press/McGraw Hill.

BBC (1962) Press release dated 12 November 1962, accessed at BBC Archives, Caversham, folder M10/23/10

Bonner, F. (2003) Ordinary Television. London: Sage Publications.

Cobley, P. (2014) Narrative (2nd edition). Abingdon, Oxon, New York: Routledge.

Couldry, N. (2003) Beyond the Hall of Mirrors? Some Theoretical Reflections on the Global Contestation of Media Power. In Couldry, N. and Curran, J. (eds). Contesting Media Power: Alternative Media in a Networked World. Maryland: Rowman \& Littlefield Publishers.

Curran, J. (2003) Global Journalism: A Case Study of the Internet. In Couldry, N. and Curran, J. (eds). Contesting Media Power: Alternative Media in a Networked World. Maryland: Rowman \& Littlefield Publishers.

Dougherty, M. \& Schneider, S. M. (2011) Web Historiography and the Emergence of New Archival Forms. In Park, D. W., Jankowski, N. W. and Jones, S. (eds). The Long History of New Media, Technology, Historiography, and Contextualising Newness, New York: Peter Laing Publishing Inc.

Fickers, A. (2012) Towards a New Digital Historicism? Doing History in the Age of Abundance. Journal of European History and Culture, 1: 1-9.

Fickers, A. and Van Den Oever, A. (2014) Experimental Media Archaeology: A Plea for New Directions. In Annie van den Oever (ed.). Techne/Technology: Researching Cinema and Media Technologies - Their Development, Use and Impact, Amsterdam University Press, 272-278.

Flinn, A., Stevens, M., and Shepherd, E. (2009) Whose Memories, Whose Archives? Independent Community Archives, Autonomy and the Mainstream, Archival Science, 9(1-2): 71-86, Springer Science+Business Media.

Keightley, E. and Pickering, M. (2012) The Mnemonic Imagination: Remembering as Creative Practice. Basingstoke, New York: Palgrave Macmillan.

Rodriguez, C. (2003) The Bishop and His Star: Citizens' Communication in Southern Chile. In Couldry, N. and Curran, J. (eds) Contesting Media Power: Alternative Media in a Networked World. Maryland: Rowman \& Littlefield Publishers.

Silvertown, J., (2009) A New Dawn for Citizen Science. Trends in Ecology \& Evolution, 24(9): 467-471.

Wake, W. (accessed 10 Nov 2017) Live TV Drama. BFI Screenonline http://www.screenon line.org.uk/tv/id/1351821/index.html

Wood, J. (2005) Prospero (BBC retirees magazine). See article at http://www.pebblemill. org/blog/2005-prospero-article-john-wood/ 